\title{
PENGEMBANGAN ALAT PEMBERI MAKAN IKAN OTOMATIS MENGGUNAKAN ARDUINO TERINTEGRASI BERBASIS IOT
}

\author{
Hidayatullah Himawan (1), Mangaras Yanu $F^{(2)}$ \\ Jurusan Teknik Informatika, Fakultas Teknik Industri, UPN “Veteran” Yogyakarta \\ Jl. Babarsari 2 Tambakbayan Yogyakarta \\ e-mail : if.iwan@gmail.com ${ }^{(1)}$, mangaras.yanu@upnyk.ac.id(2)
}

\begin{abstract}
Smart Feeding IoT based is an automatic fish feeding concept that allows for remote control in feeding and monitoring pond conditions such as water temperature, Ph levels, water clarity levels so that fish growth can be maximized by using arduino as a tool. IoT based Smart Feeding is a concept that combines architectural and mechanical electrical design in order to provide speed of movement / mobility and ease of control as well as access from any direction and time at any time in terms of automation in which all activities that occur in fish farming can ease the task of breeders fish cultivation. Information on fish ponds can be quickly detected thanks to the help of the Dallas DS18B20 sensor, pH Probe E201-BNC and TDS meter sensors which can find out the condition of pond water then the reading data is sent in real time and stored in a database. Internet of Things (IOT) Integrated Fish Farming Monitoring System to remotely control and monitor fish ponds using cloud computing is carried out with several design stages, the first stage which is an analysis of system problems to find out more about monitoring fish ponds. exist in fish cultivation activities. The output resulting from the fish feed testing is in accordance with the feed opening time set from the application as well as the calibration sensor testing of water temperature, $\mathrm{pH}$ and water clarity obtained the same results, only decimal fractions that distinguish.
\end{abstract}

\section{Keywords: Smart Feeding Internet of Things, Monitoring, Fish Feed}

Abstrak

Smart Feeding berbasis lo $T$ adalah sebuah konsep pakan ikan otomatis yang memungkinkan untuk mengontrol jarak jauh dalam pemberian pakan dan memantau/memonitoring kondisi kolam seperti suhu air, kadar $\mathrm{Ph}$, kadar kejernihan air agar pertumbuhan ikan bisa maksimal dengan menggunakan arduino sebagai alat. Smart Feeding berbasis IoT merupakan sebuah konsep yang memadu padankan desain arsitektur dan mekanikal elektrikal agar dapat memberi kecepatan gerak/mobilitas serta kemudahan kontrol juga akses dari arah mana pun dan waktu kapanpun dalam hal otomatisasi di mana semua aktivitas yang terjadi pada pembudidayaan ikan dapat meringankan tugas peternak budidaya ikan. Informasi kolam ikan dapat dengan cepat diketahui berkat bantuan sensor Dallas DS18B20, pH Probe E201-BNC dan sensor TDS meter yang di mana dapat mengetahui kondisi air kolam kemudian data hasil pembacaan di kirimkan secara real time dan disimpan pada database. Sistem Monitoring Kolam Budidaya Ikan Terintegrasi Berbasis Internet of Things (IoT) untuk mengontrol jarak jauh dan memantau kolam ikan dengan menggunakan cloud computing dilakukan dengan beberapa tahap-tahap perancangan, tahap pertama yang merupakan analisis masalah sistem untuk mengetahui lebih dalam mengenai tentang monitoring kolam ikan yang ada pada aktivitas pembudidayaan ikan.

Output yang dihasilkan dari pengujian pemberian pakan ikan sudah sesuai dengan waktu buka pakan yang diatur dari aplikasi serta pengujian sensor kalibrasi suhu air, ph dan kejernihan air didapatkan hasil yang sama, hanya pecahan decimal yang membedakan.

Kata Kunci : Smart Feeding Internet of Things, Monitoring, Pakan Ikan

\section{PENDAhUluan}

Indonesia merupakan negara yang memiliki culture sangat kuat salah satu contohnya dalam bidang pembudidayaan ikan, terlebih Indonesia adalah negara perairan. Hampir di seluruh wilayah Indonesia petani ikan merupakan usaha yang mudah dijumpai. Pembuatan danau buatan serta luasnya perairan laut di Indonesia telah memberikan kemudahan bagi masyarakat khususnya peternak budidaya ikan untuk dapat mengembangkan usaha perikanan di 
Indonesia. Usaha budidaya ikan memang sangat menjanjikan hasilnya di Indonesia, sehingga banyak sekali muncul teknologi yang sangat membantu bagi peternak budidaya ikan.

Dalam kegiatan budidaya ikan banyak pekerjaan yang harus dilakukan, beberapa hal yang penting dalam pembudidayaan ikan adalah pemberian pakan ikan dan pengontrolan terhadap kualitas air yang ada pada kolam seperti suhu air, kadar $\mathrm{pH}$ dan kejernihan air. Aktifitas untuk memberi pakan saat ini memang sudah terbantu dengan adanya alat pakan ikan otomatis. Namun untuk mengganti jadwal pakan dan memantau kondisi air tetap harus datang secara langsung ke kolam. Pengecekan kondisi kolam dengan cara manual pada alat tersebut masih memiliki kekurangan, yaitu ketika terlalu sibuk dengan aktivitas di luar rumah dan tidak sempat datang ke kolam maka akan sering terjadi kelalaian pada saat pemberian jadwal pakan. Air kolam pun jadi tidak bisa maksimal untuk dikontrol dan jika kualitas air kolam dibiarkan saja akan berakibat buruk bagi kesehatan ikan. Hal tersebut dapat mengakibatkan ikan kekurangan gizi, pertumbuhannya terhambat dan tidak merata, sakit dan bahkan bisa mengakibatkan kematian sehingga hasil panen ikan tidak akan maksimal seperti yang diharapkan

Perkembangan teknologi saat ini memang berpengaruh besar, baik yang berhubungan dengan rutinitas manusia secara langsung maupun rutinitas secara tidak langsung termasuk dalam bidang pembudidayaan ikan. Teknologi berawal dari model sistem konvensional yang kemudian bergerak maju menuju sistem yang terotomatisasi dan terkontrol jarak jauh.

Penelitian sebelumnya yang terkait dengan budidaya ikan sebagai bahan referensi pernah dilakukan oleh Dewantoro (2016) penelitian tersebut menggunakan android sebagai alat monitoring untuk mengontrol pakan dan memantau kondisi suhu kolam dari jarak jauh dengan menggunakan internet yang secara rutin mengecek suhu pada kolam. Namun, sistem tersebut masih dikembangkan hanya untuk memantau kondisi suhu air kolam saja. Penelitian lain dilakukan oleh Maulana \& Andri (2017) yang membuat sistem smart fishing untuk memantau langsung lingkungan kolam dengan menggunakan web.

Merujuk pada penelitian sebelumnya dan mengatasi kendala permasalahan diatas, maka dikembangkanlah penelitian dengan metode perancangannya yang berbeda. Bahasa pemogramannya android java dengan database MySQL terintegrasi dengan web server di mana pada penelitian ini membuat dan mengembangkan sebuah aplikasi smart feeding yang memungkinkan untuk mengontrol jarak jauh dalam pemberian pakan dan memantau/memonitoring kondisi kolam seperti suhu air, kadar $\mathrm{Ph}$, kadar kejernihan air agar pertumbuhan ikan bisa maksimal dengan menggunakan arduino sebagai alat.

\section{METODOLOGI PENELITIAN}

Penelitian ini menggunakan metode kuantitatif. Metodologi penelitian yang digunakan terdiri dari:

\subsection{Metode pengembangan sistem}

Metode yang di gunakan adalah dengan menggunakan metode (GRAPPLE) yang terdiri dari 5 tahap yaitu adalah :

\section{a. Requirements Gathering}

Pada tahap pertama yang dilakukan oleh pengembang perangkat lunak adalah mengambil informasi lengkap dari pengguna tentang sistem yang akan dibangun dengan wawancara dan quisioner. Wawancara dilakukan langsung dengan pengguna yang menginginkan adanya sistem ini dan dengan pengguna yang berhubungan langsung dengan sistem. Tahap ini menyarankan untuk mewawancarai pengguna yang memiliki kemampuan teknis. Analisis masalah, fungsi dan kebutuhan sistem termasuk dalam tahap Requirement Gathering.

\section{b. Analiysis}

Di tahap analysis yang dilakukan adalah menggali lebih dalam hasil yang diperoleh dalam tahap sebelumnya. Tahap ini mengkaji permasalahan pengguna dan menganalisis solusinya. 
Yang termasuk dalam tahap ini antara lain: pengembangan data dan informasi dari requirement gathering

c. Design (Desain dan Arsitektur)

Tahap design dilakukan untuk merancang solusi yang dihasilkan pada tahap analysis dan design dapat berjalan dua arah saling menyesuaikan sampai diperoleh rancangan yang tepat. Yang termasuk dalam tahap ini antara lain: implementasi model dan diagram yang telah dianalisis, dibuat rancangannya.

\section{d. Development}

Tahap ini ditangani oleh pengembang program untuk membangun kode program dan user interface. Pengujian program dan dokumentasi sistem dilakukan pada tahap ini.

\section{e. Deployment}

Tahap deployment adalah tahap pendistribusian produk yang dihasilkan kepada pengguna. Tahap ini mencakup instalasi dan perencanaan backup data bila diminta oleh pengguna sesuai dengan perjanjian sebelumnya

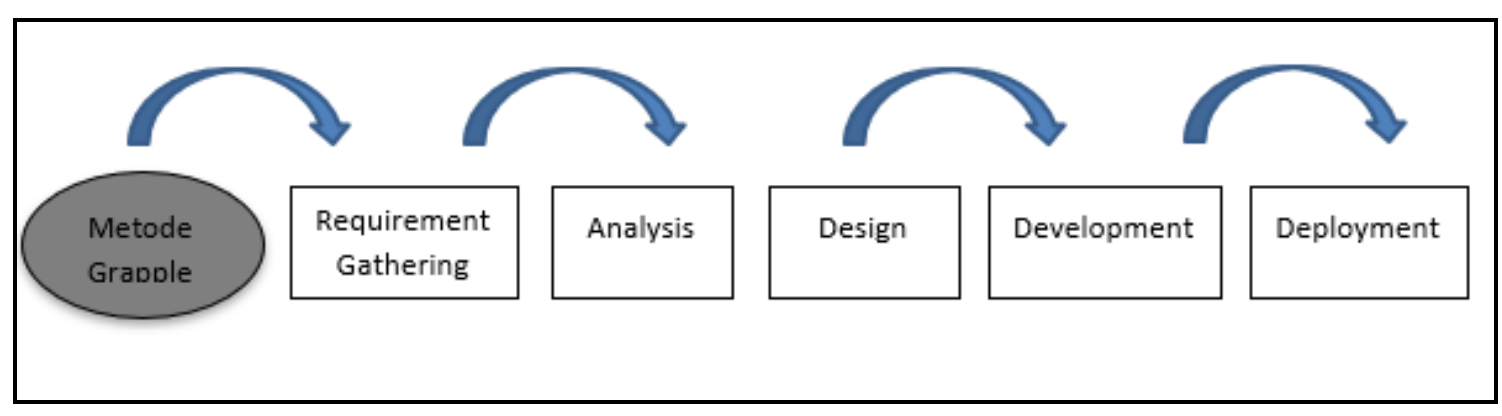

\section{Gambar 1. Metode Grapple}

\section{PERANCANGAN}

Perancangan sistem ini terdiri dari UML (Unified Modeling Language) dan perancangan tabel.

\subsection{Perancangan UML}

Perancangan ini akan menjelaskan rancangan tentang sistem aplikasi android untuk Sistem Monitoring Kolam Budidaya Ikan Terintegrasi Berbasis lot.

\section{a. Use Case Diagram}

Di bawah ini merupakan gambar dari rancangan use case user pada aplikasi android untuk Sistem Monitoring Kolam Budidaya Ikan Terintegrasi Berbasis lot dapat di lihat pada Gambar 2.

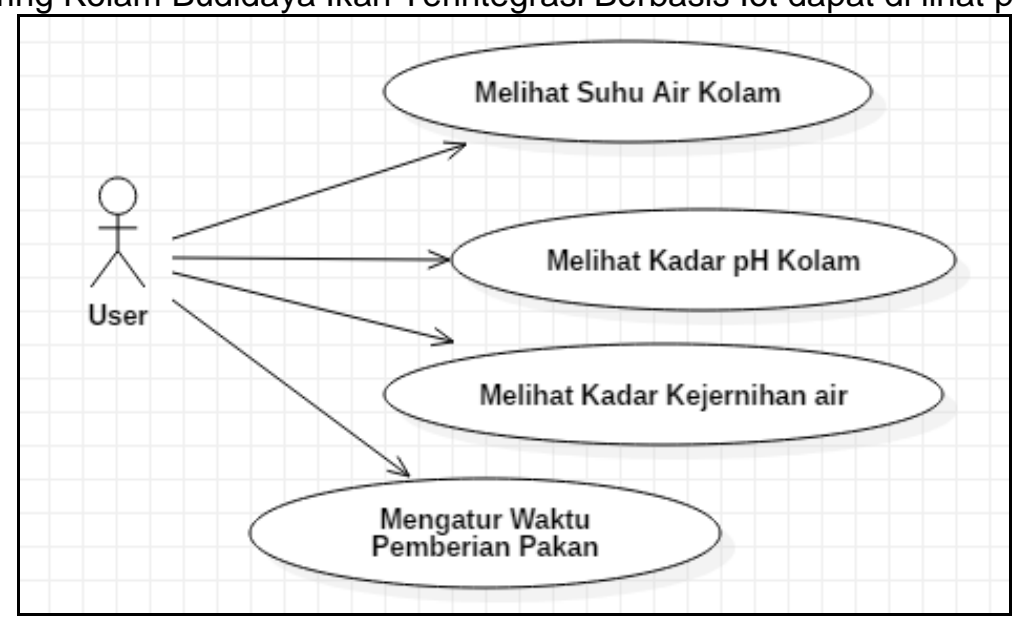

Gambar 2. Rancangan Diagram Use Case Use 
b. Activity Diagram

Diagram activity menggambarkan berbagai alur aktifitas dalam sistem, bagaimana masingmasing alir berawal, decision yang mungkin terjadi, dan bagaimana alur aktifitas dalam sistem berakhir merupakan alur kerja (workflow) atau kegiatan (aktivitas) dari sebuah sistem atau menu yang ada pada perangkat lunak. Activity Diagram juga digunakan untuk mendefinisikan urutan atau pengelompokan tampilan dari sistem user interface dimana setiap aktivitas dianggap memiliki sebuah rancangan antar muka tampilan serta rancang menu yang ditampilkan pada perangakat lunak.

\section{Diagram Activity Melihat Suhu Air Kolam}

Diagram activity melihat suhu air kolam menggambarkan berbagai alur aktifitas dalam sistem, bagaimana masing-masing alur berawal, decision yang mungkin terjadi, dan bagaimana alur aktifitas dalam sistem berakhir.

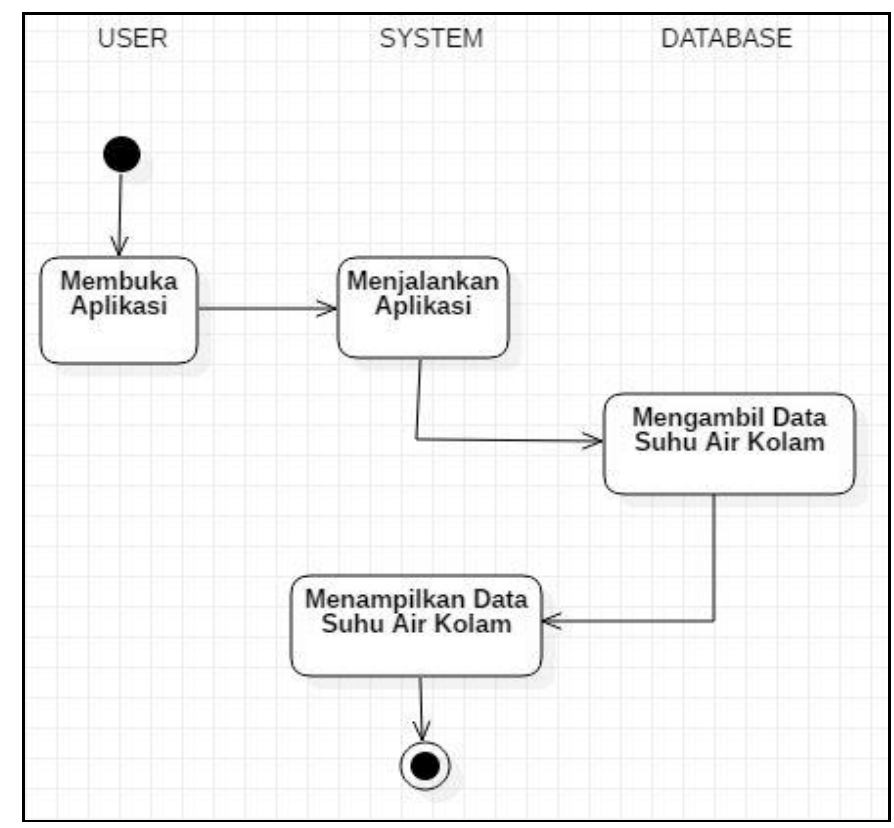

Gambar 3. Rancangan Activity Diagram Melihat Suhu Air Kolam

\section{Diagram Activity Melihat Kadar pH Kolam}

Diagram activity melihat kadar $\mathrm{pH}$ kolam menggambarkan berbagai alur aktifitas dalam sistem, bagaimana masing-masing alur berawal, decision yang mungkin terjadi, dan bagaimana alur aktifitas dalam sistem berakhir. 


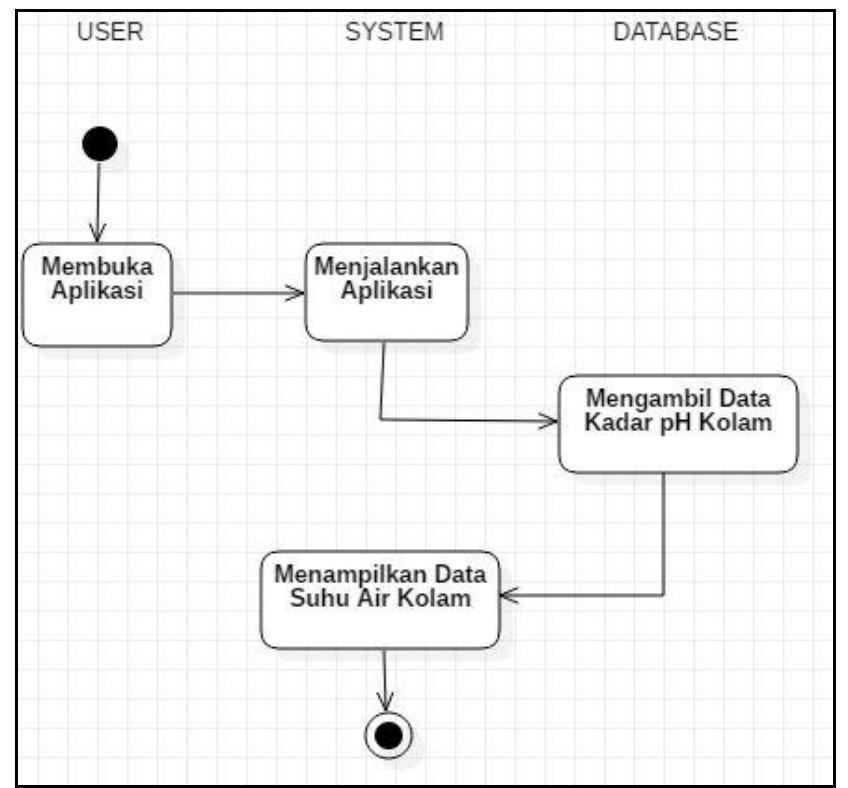

\section{Gambar 4. Rancangan Activity Diagram Melihat Kadar ph Kolam}

\section{Diagram Activity Melihat Kadar Kejernihan Air Kolam}

Diagram activity melihat kadar kejernihan air kolam menggambarkan berbagai alur aktifitas dalam sistem, bagaimana masing-masing alur berawal, decision yang mungkin terjadi, dan bagaimana alur aktifitas dalam sistem berakhir.

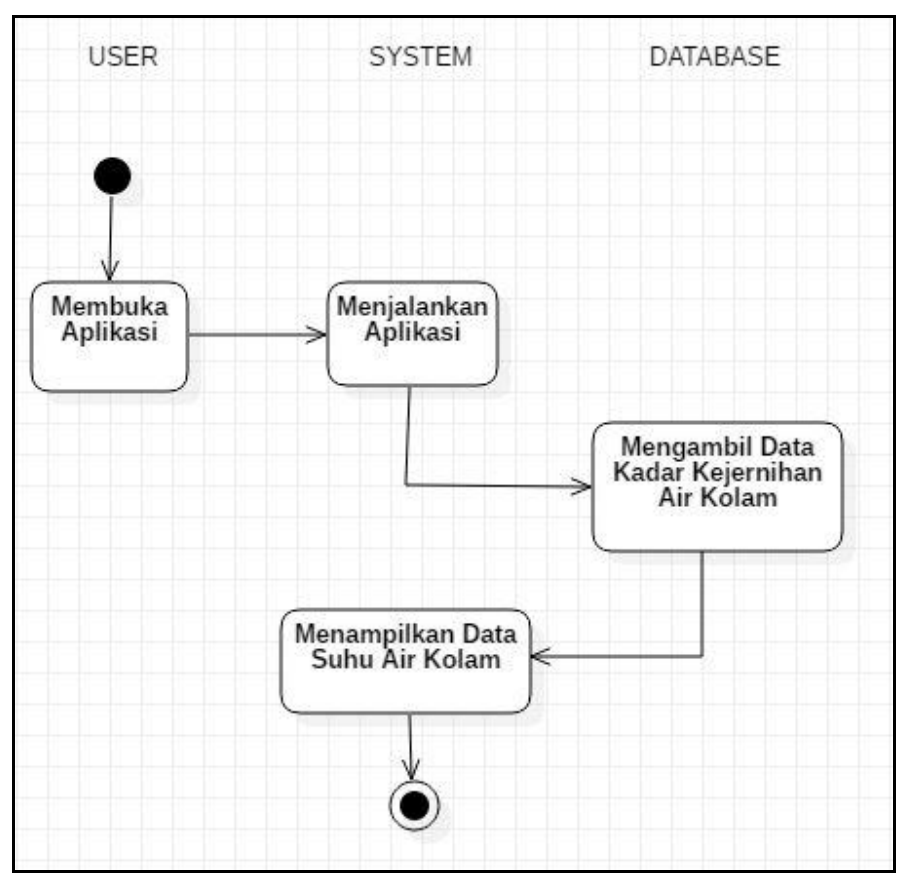

Gambar 5. Rancangan Activity Diagram Melihat Kadar Kejernihan Air Kolam Diagram Activity Mengatur Waktu Pemberian Pakan

Diagram activity mengatur waktu pemberian pakan menggambarkan berbagai alur aktifitas dalam sistem, bagaimana masing-masing alur berawal, decision yang mungkin terjadi, dan bagaimana alur aktifitas dalam sistem berakhir. 


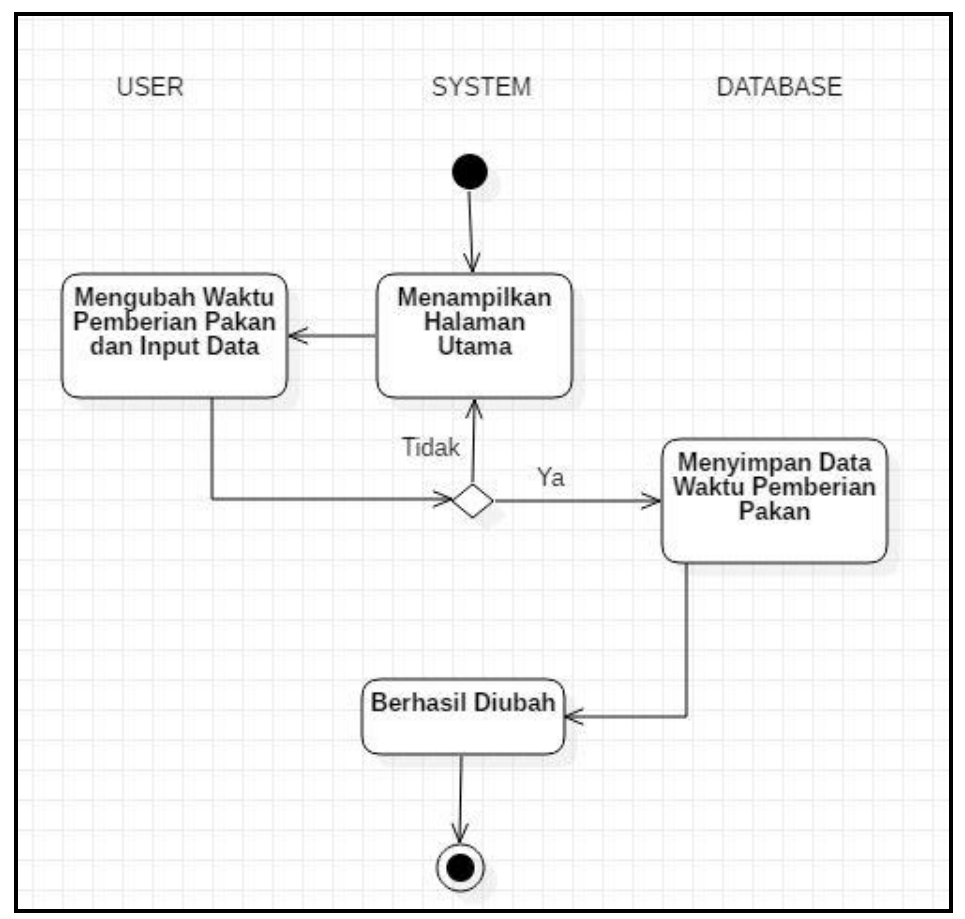

\section{Gambar 6. Rancangan Activity Diagram Mengatur Waktu Pemberian Pakan}

\section{c. Sequence Diagram}

Proses yang terjadi pada use case dan diagram activity dianalisis satu per satu dan digambarkan sehingga menghasilkan interaksi antara class pada diagram class kemudian diterjemahkan kedalam diagram sequence.

\section{Diagram Sequence Melihat Suhu Air Kolam}

Pada sequence melihat suhu air kolam menunjukkan method dan objek yang berhubungan dengan use case dan activity melihat suhu air kolam. Diagram sequence melihat suhu air kolam dapat dilihat pada Gambar 7

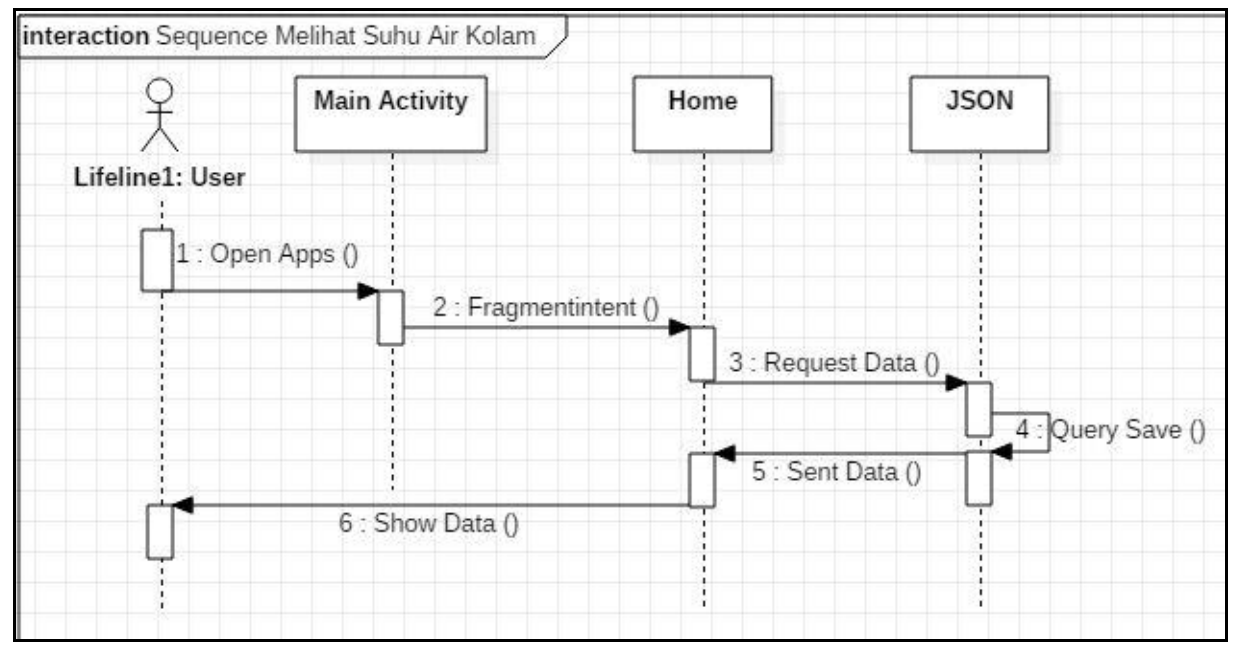

\section{Gambar 7. Rancangan Sequence Diagram Melihat Suhu Air Kolam}

\section{Diagram Sequence Melihat Kadar pH Kolam}

Pada sequence melihat kadar $\mathrm{pH}$ kolam menunjukkan method dan objek yang berhubungan dengan use case dan activity melihat kadar $\mathrm{pH}$ kolam. Diagram sequence melihat kadar $\mathrm{pH}$ dapat dilihat pada gambar dibawah. 


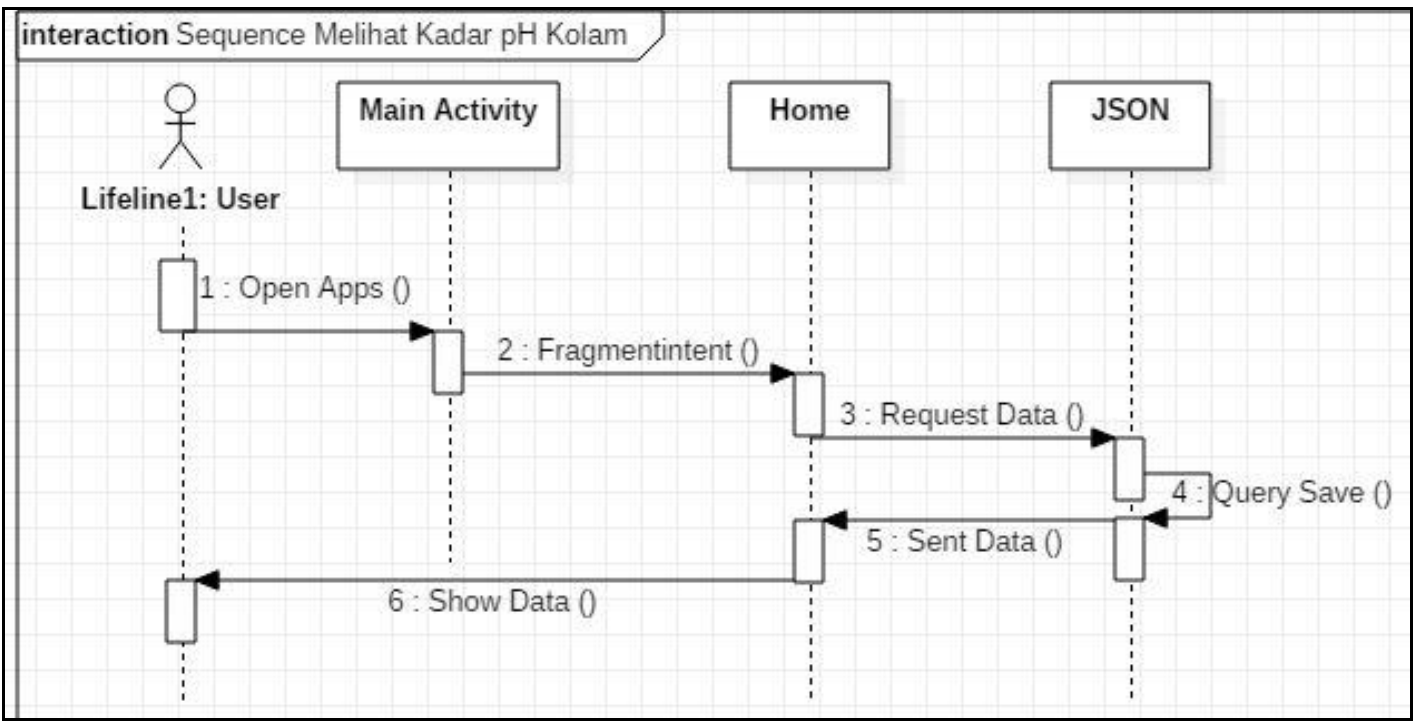

Gambar 8. Rancangan Sequence Diagram Melihat Kadar ph Kolam

\section{Diagram Sequence Melihat Kadar Kejernihan Air Kolam}

Pada sequence melihat kadar kejernihan air kolam menunjukkan method dan objek yang berhubungan dengan use case dan activity melihat kadar kejernihan air kolam. Diagram sequence melihat kadar kejernihan air kolam dapat dilihat pada gambar dibawah.

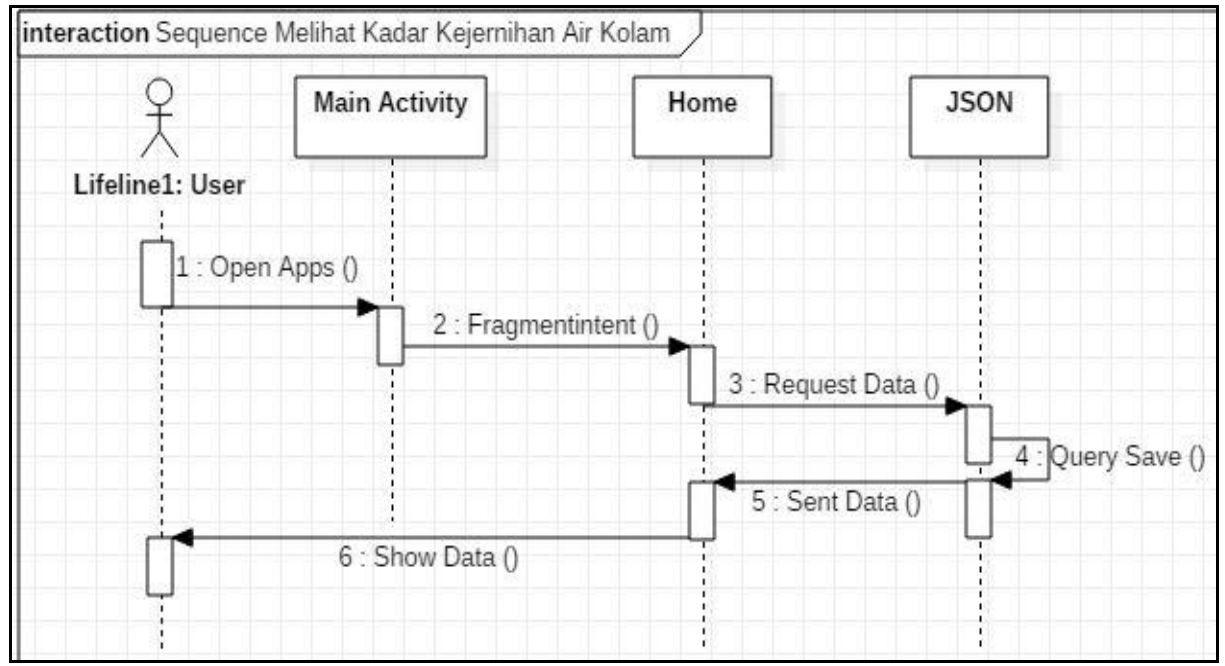

Gambar 9. Rancangan Sequence Diagram Melihat Kadar Kejernihan Air Kolam

\section{Diagram Sequence Mengatur Waktu Pemberian Pakan}

Pada sequence mengatur waktu pemberian pakan menunjukkan method dan objek yang berhubungan dengan use case dan activity mengatur pemberian pakan. Diagram sequence mengatur pemberian pakan dapat dilihat pada gambar dibawah 


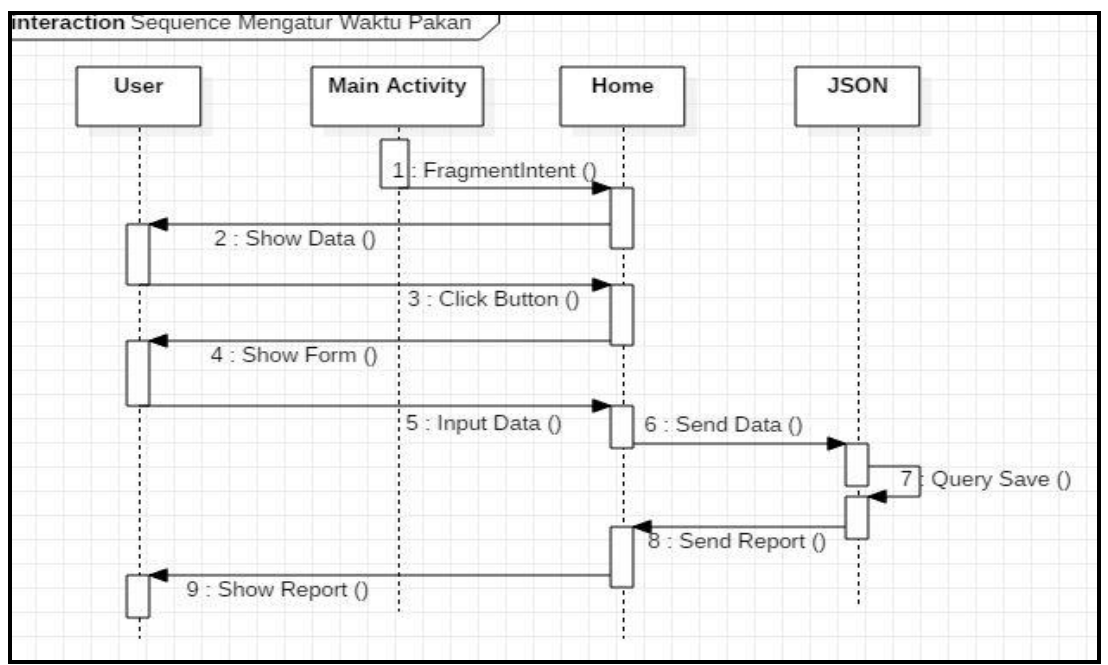

\section{Gambar 10. Rancangan Sequence Diagram Mengatur Waktu Pemberian Pakan}

\subsection{Perancangan Tabel}

Basis data dalam sistem ini hanya terdiri dua tabel yaitu tabel jadwal dan tabel keterengan.

a. Tabel Jadwal

Tabel ini merupakan tabel yang berfungsi untuk menyimpan data jam dan selang tiap jam. Adapun isi tabel jadwal adalah sebagai berikut.

Tabel 1. Jadwal

\begin{tabular}{|l|l|l|l|}
\hline \multicolumn{1}{|c|}{ Field } & \multicolumn{1}{c|}{ Tipe Data } & \multicolumn{1}{c|}{ Konstrain } & \multicolumn{1}{c|}{ Keterangan } \\
\hline id_jadwal & Int(11) & Not null, primary key & Id jadwal \\
\hline nama & Text & Not null & Nama pengguna \\
\hline username & Text & Not null & Username pengguna \\
\hline password & Text & Not null & Password pengguna \\
\hline jam_mulai & time & Not null & Jam mulai pakan \\
\hline selang & Int(11) & Not null & Selang waktu pakan \\
\hline status & Text & Not null & Status alat \\
\hline
\end{tabular}

b. Tabel Keterangan

Tabel ini merupakan tabel yang berisi data jam dan sensor yang diambil dari alat. Adapun isi tabel keterangan adalah sebagai berikut.

Tabel 2. Keterangan

\begin{tabular}{|l|l|l|l|}
\hline \multicolumn{1}{|c|}{ Field } & \multicolumn{1}{c|}{ Tipe Data } & \multicolumn{1}{c|}{ Konstrain } & \multicolumn{1}{c|}{ Keterangan } \\
\hline id_keterangan & Int(11) & Not null, primary key & Id keterangan \\
\hline temp & Double & Not null & Sensor temperatur suhu \\
\hline ph & Double & Not null & Sensor pH \\
\hline keruh & Text & Not null & Sensor kejernihan air \\
\hline jam_selanjutnya & datetime & Not null & Jam makan selanjutnya \\
\hline waktu & Datetime & Not null & Jam Sekarang \\
\hline
\end{tabular}




\section{HASIL DAN PEMBAHASAN}

Hasil dari penelitian ini akan menjelaskan mengenai hasil perancangan yang telah dilakukan, dan pengujian aplikasi. Pengujian yang dilakukan dengan melihat proses pengambilan data alat dan dari data yang ditangkap oleh setiap sensor ke aplikasi.

\section{a. Hasil Perancangan}

Setelah sistem dianalisis dan dilakukan perancangan tampilan, maka dilakukan tahap implementasi dari hasil perancangan. Hasil perancangan berupa tampilan program saat berjalan dari Sistem. Pada sub-bab ini dibahas mengenai program yang meliputi tampilan interface sistem beserta modul-modul program pembentuknya. Pada sistem aplikasi ini terdapat modul halaman home, untuk melakukan pengecekan jam pakan selanjutnya, sensor - sensor alat dan menu isi data untuk mengubah jadwal pakan dan selang waktunya.

a. Tampilan Halaman Home

Tampilan menu home android smart feeding yaitu untuk menampilkan data penggunaan alat dan sensor - sensor data kolam dapat dilihat pada gambar dibawah ini.

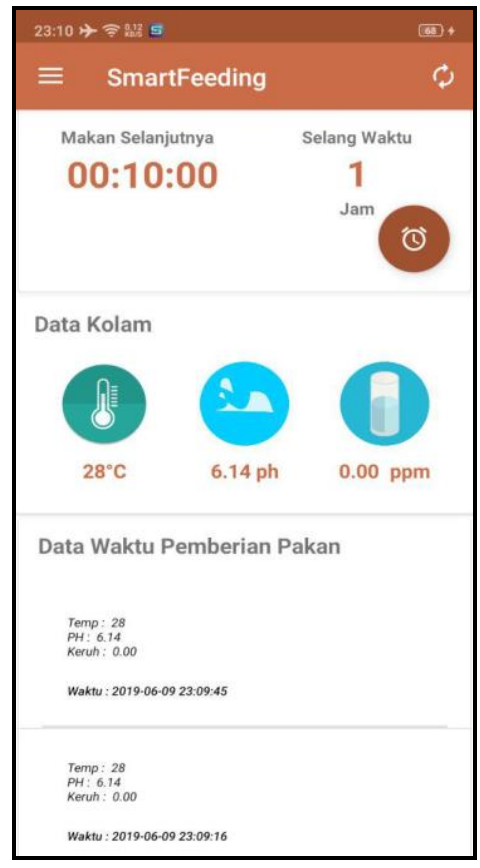

\section{Gambar 11. Tampilan Home}

\section{b. Hasil Pengujian}

Pengujian yang dilakukan berupa pengujian penggantian jadwal pakan dan ketepatan pada sensor. Pengujian akan dilakukan pada beberapa waktu dan kondisi air yang berbeda-beda seperti air murni, air panas, air dingin, air cuka, air teh dan kopi untuk dapat mengetahui juga persentase error dari data yang dihasilkan agar mengetahui akurasi data dari sensor alat. Hasil pengujian yang dilakukan tampak pada tabel berikut:

Tabel 3. Pengujian Penggantian Jadwal Pakan

\begin{tabular}{|c|c|c|c|c|}
\hline Nomor & Tanggal & $\begin{array}{c}\text { Settingan Jam } \\
\text { Makan (Aplikasi) }\end{array}$ & Waktu Buka & Berhasil Buka \\
\hline 1 & $17-07-2019$ & 15.50 & 15.50 & $\checkmark$ \\
\hline 2 & $17-07-2019$ & 15.52 & 15.52 & $\checkmark$ \\
\hline 3 & $17-07-2019$ & 15.54 & 15.54 & $\checkmark$ \\
\hline
\end{tabular}




\begin{tabular}{|l|l|l|l|l|}
\hline 4 & $17-07-2019$ & 15.56 & 15.56 & $\checkmark$ \\
\hline 5 & $17-07-2019$ & 15.57 & 15.57 & $\checkmark$ \\
\hline
\end{tabular}

Dari pengumpulan data selama beberapa kali untuk pengujian penggantian jadwal pakan yang menghasilkan alat bekerja dengan baik sesuai aturan jam makan diaplikasi.

Tabel 4. Pengujian Suhu Air

\begin{tabular}{|c|c|c|c|c|}
\hline Nomor & Tanggal & Media & $\begin{array}{c}\text { Sensor Suhu Air } \\
\text { pada Alat }\end{array}$ & $\begin{array}{l}\text { Sensor Suhu } \\
\text { Termometer }\end{array}$ \\
\hline 1 & $17-07-2019$ & Air Panas & $36.52^{\circ} \mathrm{C}$ & $37^{\circ} \mathrm{C}$ \\
\hline 2 & $17-07-2019$ & Air Mineral & $28.65^{\circ} \mathrm{C}$ & $29^{\circ} \mathrm{C}$ \\
\hline 3 & $17-07-2019$ & Air Keran & $27.26^{\circ} \mathrm{C}$ & $27^{\circ} \mathrm{C}$ \\
\hline 4 & $17-07-2019$ & Air Es & $12.08^{\circ} \mathrm{C}$ & $12^{\circ} \mathrm{C}$ \\
\hline 5 & $17-07-2019$ & Air Dingin & $20.23^{\circ} \mathrm{C}$ & $20^{\circ} \mathrm{C}$ \\
\hline \multicolumn{3}{|c|}{ Total } & 124.74 & 125 \\
\hline \multicolumn{3}{|c|}{ Rata-rata } & 24.94 & 25 \\
\hline
\end{tabular}

Dari pengumpulan data selama beberapa kali untuk pengujian sensor suhu air pada alat yang menghasilkan data sensor alat dengan sensor suhu termometer tidak jauh berbeda.

Tabel 5. Pengujian Kadar pH

\begin{tabular}{|c|c|c|c|c|}
\hline Nomor & Tanggal & Media & $\begin{array}{c}\text { Sensor Kadar pH } \\
\text { pada alat }\end{array}$ & $\begin{array}{c}\text { Sensor pH } \\
\text { meter }\end{array}$ \\
\hline 1 & $17-07-2019$ & Air Cuka & 2.04 & 2 \\
\hline 2 & $17-07-2019$ & $\begin{array}{c}\text { Air Cuka } \\
\text { +Air Keran }\end{array}$ & 3.63 & 4 \\
\hline 3 & $17-07-2019$ & Air Mineral & 7.24 & 7 \\
\hline 4 & $17-07-2019$ & Air Kopi & 9.14 & 9 \\
\hline \multicolumn{3}{|c|}{ Total } & 22.05 & 22 \\
\hline \multicolumn{3}{|c|}{ Rata-rata } & 5.51 & 5.5 \\
\hline
\end{tabular}

Dari pengumpulan data selama beberapa kali untuk pengujian kadar $\mathrm{pH}$ pada alat yang menghasilkan data sensor alat dengan sensor $\mathrm{pH}$ meter tidak jauh berbeda.

Tabel 6. Pengujian Kadar Kejernihan Air

\begin{tabular}{|c|c|c|c|c|}
\hline Nomor & Tanggal & Media & $\begin{array}{c}\text { Sensor TDS } \\
\text { pada alat }\end{array}$ & Sensor TDS meter \\
\hline 1 & $17-07-2019$ & Air Mineral & 120 & 120 \\
\hline 2 & $17-07-2019$ & Air Keran & 178 & 178 \\
\hline 3 & $17-07-2019$ & Air Teh & 316 & 316 \\
\hline 4 & $17-07-2019$ & Air Kopi & 470 & 470 \\
\hline \multicolumn{3}{|c|}{ Total } & 1084 & 1084 \\
\hline \multicolumn{3}{|c|}{ Rat } & 271 & 271 \\
\hline
\end{tabular}

Dari pengumpulan data selama beberapa kali untuk pengujian kadar kejernihan air pada sistem yang menghasilkan data sensor alat dengan sensor tds meter tidak jauh berbeda. Dari datadata hasil pengujian alat diatas, dapat disimpulkan bahwa sensor-sensor alat masih memiliki tingkat akurasi yang hampir mendekati, walaupun berbeda-beda pada setiap waktu dan media yang digunakan dikarenakan beberapa factor seperti kualitas komponen yang digunakan dan kadar air yang berbeda-beda. 


\section{KESIMPULAN DAN SARAN}

Berdasarkan hasil dari analisis, perancangan, dan pembahasan yang telah dilakukan, maka dihasilkan sebuah sistem yang dapat mengontrol pakan dan memonitoring kolam. Kesimpulan yang lebih lanjut dapat diambil pada penelitian ini antara lain:

a. Menghasilkan sistem yang dapat mengontrol jam pakan ikan yang lebih teratur.

b. Menghasilkan sistem yang dapat memonitoring air kolam ikan seperti suhu air, kadar pH dan kadar kejernihan air agar kolam ikan bisa terjaga kualitasnya.

c. Pada penelitian ini, cloud digunakan sebagai media untuk menanamkan server, dimana sistem yang berada dalam server dapat digunakan sebagai media penyimpanan data record sensor, sehingga lebih mudah di akses dan data lebih aman.

Penelitian yang telah dilakukan memiliki beberapa acuan yang telah dicapai yang dapat terlihat dalam kesimpulan. Disamping adanya pencapaian tersebut sistem ini masih memerlukan adanya pengembangan. Beberapa hal yang dapat diterapkan untuk pengembangan sistem lebih lanjut adalah sebagai berikut:

a. Pada penelitian ini, dapat dikembangkan dengan menambahkan fitur seperti mengeluarkan pakan per takaran gram.

b. Pada penelitian ini, dapat dikembangkan dengan menambahkan kamera untuk memantau situasi kolam.

c. Pada penelitian ini, dapat dikembangkan dengan menambahkan fitur untuk menentukan range kualitas suhu air, kadar $\mathrm{pH}$ dan kadar tds yang bagus.

d. Pada penelitian ini masih dapat dikembangkan lagi tidak hanya dikolam ikan tetapi juga dapat di objek objek lainya.

\section{DAFTAR PUSTAKA}

Ariyanto, E. Y., Aman, M., \& Rochmad, C. D. (n.d.). Perancangan Dan Pembuatan Sistem Penebar Pakan Ikan Jenis Pasta Otomatis Berbasis Mikrokontroler AT89S51, 2-4.

Bangun, R., Pengkondisi, A., \& Budidaya, K. (2017). Vol. 13, 13(3), 178-182.

Cipto, G., Atmaja, T., Putrada, A. G., \& Rakhmatsyah, A. (2018). Optimasi Tingkat Hidup Udang Crystal Red dengan Menerapkan Metode Fuzzy Logic Berbasis IOT, 5(2), 3649-3656.

Design And Fabrication Of An Automatic Fish Feeding System For Home Aquarium Siti Aisyah Binti Saahri Report submitted in partial fulfilment of the requirements for the award of the degree of Bachelor of Engineering ( Hons .) Mechatronics Engineering Faculty of Manufacturing Engineering Universiti Malaysia Pahang. (2015), (June).

Dewantoro, W. (2016). Jurnal IImiah Komputer dan Informatika ( KOMPUTA) Pembangunan Sistem Pantau Smart Fish Farm Menggunakan Arduino Berbasis Internet Of Things ( lot ) Terhadap Budidaya Ikan Wisnu Dewantoro Teknik Informatika - Universitas Komputer Indonesia Jurnal IImiah Komputer dan Informatika ( KOMPUTA ), 2016, 1-8.

E-journal, A., \& Elektro, J. T. (2016). Rancang bangun perangkat pemberi pakan ikan otomatis pada kolam pembenihan ikan berbasis arduino.

Irawan, D., Rosmiati, M., \& Sularsa, A. (2017). Pembangunan Sistem Monitoring Penjadwalan Pemberian Makan Ikan Lele Berbasis Sms Gateway Development System Of Monitoring Schedule Feeding For Catfish, 3(3), 1833-1838.

Ke-, P. S. (2017). C dan hasil kalibrasi dengan thermometer dihasilkan tingkat kesalahan penggunaan sensor DS18B20 adalah <2\% Kata kunci : sensor, suhu, DB18B20, Arduino uno 1.

Komaludin, D. (2018). Prototype Monitoring Suhu Tanaman Hidroponik Teknologi lot ( Internet 
Of Thing ) Abstrak, 3(1), 45-51.

Maulana, H., \& Julianto, A. M. (2017). Pembangunan System Smartfishing Berbasis Internet of Things ( Studi Kasus di Peternakan Ikan Cahaya Ikan Mas, Majalaya ), 2017, 169-174.

Mikrokontroller, M., \& Uno, A. (2014). yang asalnya pemukiman penduduk kini hampir semua.

Publikasi, N., Akhir, T., Waluyo, A., Studi, P., Elektro, T., Teknologi, F., ... Yogyakarta, U. T. (2018). Pemberi Pakan Ikan Otomatis Menggunakan ESP8266 Berbasis Internet Of Things ( IOT ) Pemberi Pakan Ikan Otomatis Menggunakan ESP8266 Berbasis Internet Of Things ( IOT).

Qalit, A., \& Rahman, A. (2017). Rancang Bangun Prototipe Pemantauan Kadar pH dan Kontrol Suhu Serta Pemberian Pakan Otomatis pada Budidaya Ikan Lele Sangkuriang Berbasis loT, 2(3), 8-15.

Sarjana, P., \& li, M. (2010). An Intelligent Fish Feeder System Nurul Husna Binti Abdul Razak This report in partial fulfillment of the requirements for the award of Bachelor of Electronic Engineering ( Industrial Electronics ) With Honours Faculty of Electronic and Computer Engineering Universiti Teknikal Malaysia Melaka April 2010, (April).

Teknikal, U. (2007). Automatic Fish Feeder for Cultivation Pond, (April).

Weku, H. S., Poekoel, E. V. C., Robot, R. F., \& Eng, M. (2015). Rancang Bangun Alat Pemberi Pakan Ikan Otomatis Berbasis Mikrokontroler, 5(7), 54-64. 